\title{
Responses of the Toll-like receptor and melanoma differentiation- associated protein 5 signaling pathways to avian infectious bronchitis virus infection in chicks
}

\author{
Yining He, Zhiwen Xie, Jinglong Dai, Yanjie Cao, Jinlian Hou, Yansheng Zheng, Tianchao Wei, \\ Meilan Mo ${ }^{凶}$, Ping Wei ${ }^{\circledR}$ \\ College of Animal Science and Technology, Guangxi University, Nanning 530004, China
}

Avian infectious bronchitis virus (IBV) is a Gammacoronavirus in the family Coronaviridae and causes highly contagious respiratory disease in chickens. Innate immunity plays significant roles in host defense against IBV. Here, we explored the interaction between IBV and the host innate immune system. Severe histopathological lesions were observed in the tracheal mucosa at 3-5 days post inoculation (dpi) and in the kidney at $8 \mathrm{dpi}$, with heavy viral loads at 1-11 and 1-28 dpi, respectively. The expression of mRNAs encoding Toll-like receptor (TLR) 3 and TLR7 were upregulated at 3-8 dpi, and that of TIR-domain-containing adapter-inducing interferon (IFN) $\beta$ (TRIF) was upregulated at $21 \mathrm{dpi}$ in the trachea and kidney. Myeloid differentiation primary response protein 88 (MyD88) was upregulated in the trachea during early infection. Tumor necrosis factor receptor-associated factor (TRAF) 3 and TRAF6 were upregulated expression in both tissues. Moreover, melanoma differentiation-associated protein 5 (MDA5), laboratory of genetics and physiology 2 (LGP2), stimulator of IFN genes (STING), and mitochondrial antiviral signaling protein (MAVS), as well as TANK binding kinase 1 (TBK1), inhibitor of kappaB kinase (IKK) $\varepsilon$, IKKa, IKK $\beta$, IFN regulatory factor (IRF) 7 , nuclear factor of kappaB (NF-kB), IFN- $\alpha$, IFN- $\beta$, various interleukins(ILs), and macrophage inflammatory protein-1 $\beta$ (MIP-1 $\beta$ ) were significantly upregulated in the trachea and downregulated in the kidney. These results suggested that the TLR and MDA5 signaling pathways and innate immune cytokine were induced after IBV infection. Additionally, consistent responses to IBV infection were observed during early infection, with differential and complicated responses in the kidney.

KEYWORDS infectious bronchitis virus; Toll-like receptor signal pathway; melanoma differentiation-associated protein 5 signal pathway; cytokines

\section{INTRODUCTION}

Avian infectious bronchitis virus (IBV) is a prototype coronavirus containing a single-stranded positive-sense Received: 1 December 2015, Accepted: 27 January 2016 Published online: 19 February 2016

$\triangle$ Correspondence:

Meilan Mo, Phone/Fax: +86-771-323-8118,

Email: momeilan@163.com

ORCID: 0000-0003-3903-0509

Ping Wei, Phone: +86-771-323-5638, Fax: +86-771-323-5650,

Email: pingwei8@126.com

ORCID: 0000-0003-1159-5145
RNA genome (Cook et al., 2012) and has been identified as the causative agent of highly contagious respiratory disease in chickens. Since the first description in 1931 as a respiratory disease in chicks, many IBVs, which replicate in the respiratory tract, alimentary tract, kidney, and reproductive system and cause relevant pathological damage, have been reported worldwide (Schalk and Hawn, 1931; Yu et al., 2001; Benyeda et al., 2009; Fan et al., 2012).

In the poultry industry, IBV causes serious economic losses. Direct losses result from mortality, secondary bacterial infections, decreased weight gain, poor produc- 
tion and egg quality, and false layers, whereas indirect losses arise from increasing costs and challenges in IBV prevention (Awad et al., 2014). There are multiple known strains of IBV, and increasing numbers of variants have emerged continuous recombination, resulting in more diversified and complicated genotypes and serotypes (Li et al., 2012; Mo et al., 2013; Chen et al., 2015). With poor vaccine crossprotection between different serotypes, such diversity makes it difficult to prevent and control IBV infection using vaccines. Moreover, IBV is also similar to human coronaviruses, such as severe acute respiratory syndrome coronavirus (SARS-CoV) and Middle East respiratory syndrome coronavirus (Xu et al., 2015).

The innate immune response is the first line of host defense against exogenous pathogens and consists of a network of mechanisms, molecules, and cells, particularly pattern recognition receptors (PRRs), which function to identify various pathogen-associated molecular patterns (PAMPs). Toll-like receptors (TLRs) and RIG-Ilike receptors (RLRs) are two primary and important PRRs involved in recognition of viral components. Endosomal TLR3 and TLR7 recognize viral double-stranded RNA (dsRNA) and single-stranded RNA (ssRNA), respectively (Mogensen, 2009). Upon binding to their respective ligands, TLR3 recruits the adaptor TIR domaincontaining adaptor inducing interferon (IFN)- $\beta$ (TRIF), and TLR7 recruits Myeloid differentiation primary response protein 88 (MyD88). TRIF associates with tumor necrosis factor (TNF) receptor-associated factor (TRAF) 3 and TRAF6, whereas MyD88 only interacts with TRAF6. In the downstream response, TRAF6 phosphorylates the transcription factor IFN regulatory factor (IRF) 7 directly or activates the transforming growth factor $\beta$-activated kinase 1 (TAK1) complex to bind to the inhibitor of kappaB kinase (IKK) complex, composed of IKK $\alpha$, IKK $\beta$, and IKK $\gamma$, and leads to activation of nuclear factor of kappaB $(\mathrm{NF}-\kappa \mathrm{B})$. Active NF- $\mathrm{NB}$ translocates into the nucleus from the cytoplasm and induces the expression of inflammatory cytokines and chemokines, including interleukin (IL)-1 $\beta$, IL-6, IL-12, IL-8, macrophage inflammatory protein (MIP)-1 $\beta$, and regulated on activation, normal $\mathrm{T}$ expressed and secreted (RANTES). On the other hand, TRAF3 recruits the IKKrelated kinases TANK-binding kinase 1 (TBK1) and IKK $\varepsilon$, resulting in phosphorylation of IRF7. The phosphorylated IRF7 translocates into the nucleus and then activates the promoters of type I IFNs and IFN-inducible gene expression (Takeuchi and Akira, 2009; Kawasaki and Kawai, 2014). Notably, some downstream signaling molecules are intersectional with other TLRs and RLRs.

RLRs are cytoplasmic RNA helicases that recognize viral RNA in the cytoplasm; RIG-I senses the 5'-triphos- phate group and blunt end of short dsRNAs or ssRNA hairpins, and melanoma differentiation-associated protein 5 (MDA5) detects long-duplex RNAs or dsRNA replication intermediates of positive-strand viruses $(\mathrm{Wu}$ et al., 2013). The activated RLRs interact with the adaptor mitochondrial antiviral signaling protein (MAVS), thereby directly binding to TRAF3 or TRAF6 and TRAF2. The recruitment of TRAF6 and TRAF3, which is responsible for its E3 ubiquitin ligase activity for the assembly of the IKK $\varepsilon$ and TBK1 complex, leads to the activation of NF- $\mathrm{KB}$ and IRF7, promotes the production of IL-8 and IL-12, and enhances the induction of type I IFN (Nakhaei et al., 2009). The RIG-I gene has not been identified in chickens, and the MDA5 signaling pathway has been shown to mediate type I IFN induction, with laboratory of genetics and physiology 2 (LGP2) function as a positive regulator (Zou et al., 2009; Liniger et al., 2011). The novel stimulator of IFN genes (STING) protein has been found in the endoplasmic reticulum and mitochondrial membrane in DF-1 cells and has been shown to activate both IRF7 and NF- $\mathrm{KB}$ transcription pathways to induce IFN- $\beta$ through interactions with MDA5 and MAVS (Cheng et al., 2015).

Studies on the interaction between coronavirus and the innate immune responses of their hosts have suggested that infection by coronaviruses, such as SARS-CoV, mouse hepatitis viruses (MHVs), and porcine epidemic diarrhea virus (PEDV), could activate the TLR signal through both TRIF- and MyD88-driven pathways (Sheahan et al., 2008; Frieman et al., 2009; Totura et al., 2015), resulting in the upregulation of TLR, cytokine, and chemokine expression and providing effective intrinsic antiviral immune responses (Law et al., 2009; Dosch et al., 2009; Mazaleuskaya et al., 2012; Cao et al., 2015). RIG-I is upregulated during MHV infection, and viral recognition by RIG-I and MDA5 is the driving force for the activation of IRF3 and the ensuing induction of IFN- $\beta$ (Li et al., 2010). Several coronaviruses, including IBV, have evolved evasive strategies to avoid immunological defense mechanisms from the host by utilizing innate immune signaling molecules (Zhong et al., 2012; Kint et al., 2015). SARS-CoV can negatively regulate the assembly of STING-MAVS-TBK1/IKK $\varepsilon$ complexes required for activation of IRF3 to disrupt antiviral defenses (Sun et al., 2012).

Transcriptional analysis of the tracheal mucosal and kidneys in IBV-infected chickens have identified abundant differentially expressed genes. Multiple innate immune genes, including TLRs, MDA5, type I IFNs, cytokines, chemokines, and signal transduction molecules, are activated locally, forming a large network (Guo et al., 2008; Cong et al., 2013; Smith et al., 2015). Furthermore, the mRNA expression levels of type I IFNs, inflammatory cytokines, and chemokines are altered in 
IBV-infected tissues (Jang et al., 2013; Dar et al., 2014; Okino et al., 2014; Nii et al., 2014). However, the relationship between IBV and the host innate immune system is poorly understood, and the specific mechanisms of the innate immune response against IBV infection through the TLR and MDA5 signaling pathways remain unclear.

Although IBV can replicate in various tissues, the natural infection of IBV first occurs in the respiratory tract epithelium and then spreads to other tissue epithelia (Cavanagh, 2005). The tissue tropism and pathogenicity of IBV are varied and dependent on the strain; however, some viruses lead to respiratory distress, nephritis with urate deposits, and enteric or reproductive diseases (Ignjatovic et al., 2002; Chousalkar et al., 2007; Cavanagh, 2007), and the infection mechanism related with tropism of IBV in different epithelial cells has been studied (Wickramasinghe et al., 2011). However, whether the intrinsic immune responses against IBV differ among infected tissues is unknown.

In the present study, we performed a comprehensive analysis of TLR and MDA5 signaling pathways and innate immune cytokine responses to IBV infection in host trachea and kidney tissues at both the mRNA and protein levels. The results showed considerable activation of TLR and MDA5 signaling pathways and induction of innate immune cytokines in the trachea, but downregulation of these components in the kidney. This is the first study to comprehensively address TLR and MDA5 signaling pathway responses to IBV in chicks and provide essential information to further improve our understanding of the immune pathogenic mechanism of avian coronaviruses.

\section{MATERIALS AND METHODS}

\section{Virus}

The pathogenic IBV strain Massachusetts 41 (M41) used in this study was purchased from China Institute of Veterinary Drug Control (Beijing, China) and propagated in 10-day-old specific pathogen-free (SPF) chicken embryos (Beijing Merial Vital Laboratory Animal Technology Co., Ltd). The infected allantoic fluid was harvested at $72 \mathrm{~h}$ postinoculation, confirmed to lack other pathogens as analyzed by reverse transcription polymerase chain reaction (RT-PCR) and bacterial culture, titrated in 10-day-old SPF chicken embryos, and finally stored at $-80^{\circ} \mathrm{C}$ before animal infection.

\section{Chicks}

The SPF white leghorn chicks used in this study were self-hatched. The chicks were raised in a sterile, quiet, comfortable animal room of the Institute of Animal Science and Technology of Guangxi University until reach- ing 14 days of age. Sterile food and water were provided ad libitum.

\section{Experimental design}

Forty-eight 2-week-old chicks were randomly allocated to two groups of 24 chicks each and raised separately in two isolation rooms with individual ventilation. Chicks from group A were inoculated oculonasally with $0.2 \mathrm{~mL}$ of $10^{6} \mathrm{EID}_{50}$ of IBV M41 allantoic fluid per chick. Chicks from group B were inoculated with $0.2 \mathrm{~mL}$ sterilized negative allantoic fluid in the same manner. Clinical symptoms were observed and recorded daily. At 1, 3, $5,8,11,14,21$, and 28 days post inoculation (dpi), three birds in each group were bled before euthanasia and necropsy. The trachea and kidney tissues were collected aseptically. Whole blood was collected, and sera were separated enzyme-linked-immunosorbent assay (ELISA). All samples were stored appropriately and immediately.

\section{Histopathology analyses}

After washing in phosphate-buffered saline (PBS), trachea and kidney tissues were fixed in $4 \%$ paraformaldehyde solution for 1 day, embedded in paraffin wax, cut into 3- $\mu \mathrm{m}$-thick sections (Leica RM4450, Germany), and stained with hematoxylin and eosin using standard histological procedure. The slides were examined by light microscopy (Nikon, Japan).

\section{RNA extraction and reverse transcription}

Equiponderant trachea and kidney tissues from each chick at various time points were prepared. The tracheal lumen was flushed with RL buffer repeatedly to lyse the mucosal tissue for RNA extraction, and kidney tissue was homogenized with RL buffer on ice. Total RNA was extracted using a MiniBEST Universal RNA Extraction Kit (TaKaRa, Shiga, Japan), including a gDNA Eraser Spin Column for treating DNA contamination according to the manufacturer's instructions. The concentration of RNA and the A260/A280 ratio were measured using an ultralow volume spectrometer (Biodrop, UK), and agarose gel electrophoresis was used to detect the integrity of the extracted RNA. A PrimeScript RT reagent Kit (TaKaRa) was used in cDNA synthesis for real-time PCR. Five hundred nanograms of total extracted RNA was added to $10 \mu \mathrm{L}$ of reaction reagent including random 6 mers, oligo dT primers, PrimeScript RT Enzyme Mix I, and buffer. The mixture was then incubated at 37 ${ }^{\circ} \mathrm{C}$ for $15 \mathrm{~min}$ and $85{ }^{\circ} \mathrm{C}$ for $5 \mathrm{~s}$ for preparation of cDNA. cDNA was then stored at $-20{ }^{\circ} \mathrm{C}$.

\section{Real-time quantitative PCR (qPCR) for gene expression analysis}

Absolute and relative quantification analyses were used to determine the absolute copy numbers of IBV RNA and the levels of mRNA expression of target genes, re- 
Table 1. Primers used in this study.

\begin{tabular}{|c|c|c|c|c|}
\hline Gene & Sequences $\left(5^{\prime}-3^{\prime}\right)^{a}$ & $\begin{array}{l}\text { Amplicon } \\
\text { size (bp) }\end{array}$ & $\begin{array}{l}\text { Annealing } \\
\left({ }^{\circ} \mathrm{C}\right)\end{array}$ & Accession no. \\
\hline$I B V-N$ & $\begin{array}{l}\text { F:CAGAAGAAGGGCTCTGCATTAC } \\
\text { R:AGGTTGAGCATTGCCGTAACAC }\end{array}$ & 200 & 60 & FJ548847.1 \\
\hline TLR3 & $\begin{array}{l}\text { F:GCAACACTTCATTGAATAGCCTTGAT } \\
\text { R:GCCAAACAGATTTCCAATTGCATGT }\end{array}$ & 92 & 62.5 & EF137861.1 \\
\hline TLR7 & $\begin{array}{l}\text { F:AAGTCCCGGTATGTTCAGCT } \\
\text { R:GGACAGGGTATTGTTCATAGC }\end{array}$ & 132 & 58.1 & NM_0001011688.2 \\
\hline MyD88 & $\begin{array}{l}\text { F:CAGCGAGCAATAGCATCCAG } \\
\text { R:CAACAGAGCCACCTTGTATC }\end{array}$ & 104 & 61 & NM_001030962.1 \\
\hline TRIF & $\begin{array}{l}\text { F:TTCAGCCATTCTCCGTCCTC } \\
\text { R:GCCAATGATGCTTCCACAG }\end{array}$ & 120 & 60 & NM_001081506.1 \\
\hline MDA5 & $\begin{array}{l}\text { F:CAGCCAGTTGCCCTCGCCTCA } \\
\text { R:AACAGCTCCCTTGCACCGTCT }\end{array}$ & 210 & 60 & NM_001193638 \\
\hline LGP2 & $\begin{array}{l}\text { F:CCAGAATGAGCAGCAGGAC } \\
\text { R:AATGTTGCACTCAGGGATGT }\end{array}$ & 109 & 60 & XM_004948615 \\
\hline MAVS & $\begin{array}{l}\text { F:CCTGACTCAAACAAGGGAAG } \\
\text { R:AATCAGAGCGATGCCAACAG }\end{array}$ & 123 & 60 & NM_001012893 \\
\hline STING & $\begin{array}{l}\text { F:TGACCGAGAGCTCCAAGAAG } \\
\text { R:CGTGGCAGAACTACTTTCAG }\end{array}$ & 82 & 60 & XM_001232170 \\
\hline TBK1 & $\begin{array}{l}\text { F:AAGAAGGCACACATCCGAGA } \\
\text { R:GGTAGCGTGCAAATACAGC }\end{array}$ & 170 & 58.1 & NM_001199558.1 \\
\hline$I K K \varepsilon$ & $\begin{array}{l}\text { F:TGGATGGGATGGTGTCTGAAC } \\
\text { R:TGCGGAACTGCTTGTAGATG }\end{array}$ & 117 & 60 & XM_428036.4 \\
\hline TRAF3 & $\begin{array}{l}\text { F:GGACGCACTTGTCGCTGTTT } \\
\text { R:CGGACCCTGATCCATTAGCAT }\end{array}$ & 107 & 60 & XM_004936348.1 \\
\hline TRAF6 & $\begin{array}{l}\text { F:GATGGAGACGCAAAACACTCAC } \\
\text { R:GCATCACAACAGGTCTCTCTTC }\end{array}$ & 170 & 60 & XM_004941547.1 \\
\hline$I K K \alpha$ & $\begin{array}{l}\text { F:GAGGGGTGGAGGCTTAGATC } \\
\text { R:ACTTTCCTCGGGATGCAAGA }\end{array}$ & 141 & 60 & NM_001012904.1 \\
\hline$I K K \beta$ & $\begin{array}{l}\text { F:TACAGGCAATCCAGACCTTCG } \\
\text { R:GACTGCCACTAACAGGACCAC }\end{array}$ & 234 & 60 & NM_001031397.1 \\
\hline$N F-\kappa B p 65$ & $\begin{array}{l}\text { F:CATTGCCAGCATGGCTACTAT } \\
\text { R:TTCCAGTTCCCGTTTCTTCAC }\end{array}$ & 102 & 60 & NM_205129.1 \\
\hline IRF7 & $\begin{array}{l}\text { F:ACACTCCCACAGACAGTACTGA } \\
\text { R:TGTGTGTGCCCACAGGGTTG }\end{array}$ & 134 & 58.5 & NM_205372.1 \\
\hline$I F N-\alpha$ & $\begin{array}{l}\text { F:GGACATGGCTCCCACACTAC } \\
\text { R:TCCAGGATGGTGTCGTTGAAG }\end{array}$ & 75 & 61.3 & X92476.1 \\
\hline$I F N-\beta$ & $\begin{array}{l}\text { F:TTCTCCTGCAACCATCTTC } \\
\text { R:GAGGTGGAGCCGTATTCT }\end{array}$ & 82 & 62.5 & AY974089.1 \\
\hline$I L-1 \beta$ & $\begin{array}{l}\text { F:AACCCGACCAGGTCAACA } \\
\text { R:CGGTACATACGAGATGGAAAC }\end{array}$ & 101 & 61.3 & AJ245728.1 \\
\hline IL-6 & $\begin{array}{l}\text { F:ATCCCTCCTCGCCAATCTG } \\
\text { R:CCTCACGGTCTTCTCCATA }\end{array}$ & 103 & 61.3 & HM179640.1 \\
\hline IL-8 & $\begin{array}{l}\text { F:CACAGCTCCACAAAACCTCA } \\
\text { R:GTCCTACCTTGCGACAGAGC }\end{array}$ & 118 & 60 & NM_205498 \\
\hline IL-10 & $\begin{array}{l}\text { F:ATGCTGCGCTTCTACACA } \\
\text { R:CCATGCTCTGCTGATGACT }\end{array}$ & 73 & 61.3 & AY647438.1 \\
\hline IL-12 & $\begin{array}{l}\text { F:TCTGCTAAGACCCACGAGA } \\
\text { R:TTGACCGTATCATTTGCCCAT }\end{array}$ & 82 & 60 & NM_213571 \\
\hline$M I P-1 \beta$ & $\begin{array}{l}\text { F:TGCTGGTGTTGTGTTCATC } \\
\text { R:GTCCTGTACCCAGTCGTT }\end{array}$ & 73 & 63 & L34553.1 \\
\hline GAPDH & $\begin{array}{l}\text { F:GGTGGTGCTAAGCGTGTTA } \\
\text { R:CCCTCCACAATGCCAA }\end{array}$ & 179 & 60.5 & X01578.1 \\
\hline TBP & $\begin{array}{l}\text { F:TAGCCCGATGATGCCGTAT } \\
\text { R:TTCCCTGTGTCGCTTGC } \\
\end{array}$ & 147 & 62.5 & D83127 \\
\hline
\end{tabular}

Note: ${ }^{a}$ Primers for TLR3, IFN- $\alpha$ were previously reported (Karpala et al., 2008), and those for GAPDH and TBP were also previously reported (Li et al., 2005). F indicates forward primer; $\mathrm{R}$ indicates reverse primer. 
spectively. All primers pairs used for constructing recombinant plasmids and real-time PCR detection are listed in Table 1. Real-time PCR using SYBR Premix Ex Taq II mix (TaKaRa) was performed on an iQ5 instrument (Bio-Rad, Hercules, USA) as previously described (Mo et al., 2011). The annealing temperatures for each gene are listed in Table 1. The IBV RNA copy number was calculated according to the standard curve using the cycle threshold $(C t)$. The relative expression ratios of target genes were calculated using $C t$ values and amplification efficiencies by the Pfaffl method operated in REST software, as previously described (Pfaffl et al., 2002). Several endogenous reference genes were evaluated to determine their suitability in IBV-infected chickens (data not shown), and glyceraldehyde 3-phosphate dehydrogenase (GAPDH) and TATA-box-binding protein (TBP) were used to normalize fold changes in expression.

\section{ELISA for measurement of cytokines in tissues and IBV IgG in serum}

The concentrations of IFN- $\alpha$, IFN- $\beta$, IL- $1 \beta$, IL- 6 , IL-8, IL-10, IL-12, and MIP-1 $\beta$ in the trachea and kidney tissues were measured using a commercially available ELISA kit (Chenglin Biotechnology, Beijing, China) according to the manufacturer's instructions. To determine the exact concentration of target protein, standards were added to generate a standard curve, which was used to calculate the concentration based on the OD values. Each sample was analyzed in triplicate. The IBV-specific IgG antibody in serum was measured according to methods described in our previous report (Li et al., 2012), and the purified IBV N protein was used as antigen for the reaction. The OD values were read using a microplate reader (iMark; Bio-Rad) at $450 \mathrm{~nm}$ absorbance.

\section{Statistical analysis}

Data are expressed as the mean \pm standard error of the mean (SEM). To identify significant differences, mean comparisons were performed using one-way analysis of variance (ANOVA) for viral load and Student's t tests for protein levels in SPSS17.0 software (SPSS Inc., Chicago, IL, USA). The results were considered to be statistically significant when the $P$ value was less than 0.05 .

\section{RESULTS}

\section{Clinical signs and histopathological lesions}

Several chicks in group A showed slight sneezing at 2 and 3 dpi. At 4 dpi, clinical signs became obvious in most chicks and included depression, ruffled feathers, tracheal rales, frequently shaking, mouth breathing, and coughing. The clinical signs were reduced at $11 \mathrm{dpi}$ and almost completely disappeared at 14 dpi. At 3 and 5 dpi, hyperemia catarrhal exudates in tracheal mucosa were observed in group A, but no distinct gross lesions in the kidneys or other organs were observed.

Similar results were observed in analysis of histopathological changes. The tracheal mucosa exhibited severe lesions at 3 and 5 dpi (Figure 1B, 1C), and slight recovery was observed from $8 \mathrm{dpi}$, with chicks showing a return to normal histopathological features by 14 dpi (Figure $1 \mathrm{D}, 1 \mathrm{~F})$. Lesions in the kidneys were discovered at 8 dpi (Figure 1H) and lasted to $28 \mathrm{dpi}$; however, the severity of lesions was reduced beginning at 14 dpi. No birds in any group died during the experiment. All chicks in the control group showed no clinical signs, gross lesions, or pathological changes.

\section{The dynamics of IBV viral RNA and changes in IBV-specific IgG in infected chicks}

The kinetics of viral loads in the trachea and kidney are illustrated in Figure 2. In group A, IBV RNA was detected in the trachea at $1 \mathrm{dpi}$ and reached a peak at $5 \mathrm{dpi}$ with a viral copy number of around $4.8 \times 10^{5}$ copies $/ \mu \mathrm{L}$. Additionally, the level remained high at $11 \mathrm{dpi}$. However, from 14 to $28 \mathrm{dpi}$, viral load in the trachea was barely detectable. The viral load in the kidney was lower than that in the trachea, with a peak at about $3.53 \times 10^{2}$ copies $/ \mu \mathrm{L}$ at $5 \mathrm{dpi}$. IBV RNA was not found in the trachea or kidney of chicks in control group B. The level of IBV-specific IgG in serum was measured, and specific seropositivity was detected in group A from 5 to 28 dpi. The IgG level increased beginning at $5 \mathrm{dpi}$ and reached a peak at $14 \mathrm{dpi}$, showing a gradual decrease thereafter, with full degradation by 28 dpi (Figure 3 ).

\section{Transcription profiles of TLR and MDA5} signaling pathway responses to IBV infection Changes in the mRNA levels of TLR3,TLR7, and their adaptor molecules in IBV-infected tissues are illustrated in Figure 4A and 4B. The mRNA expression levels of TLR3, TLR7, and $M y D 88$ were significantly upregulated at 1-11 dpi in the trachea and $21 \mathrm{dpi}$ in the kidneys of infected chicks compared with those in control chicks. However, some molecules were downregulated in the kidney. Taken together, these results showed that TLR3, TLR7, and their adaptor molecules were activated during the early stages of infection. However, the significant upregulation of TLR7 and TRIF at 21 dpi suggested that these molecules may be involved in the later stages of infection.

Interestingly, the transcriptional regulation of $M D A 5$ and its adaptor molecules varied in the two tissue types (Figure 4C, 4D). In the trachea, significant upregulation of $M D A 5$ was detected throughout the experiment. Additionally, $L G P 2$ was upregulated from $1 \mathrm{dpi}$ and STING was upregulated from 2 dpi, with significant upregulation until 21 dpi. Moreover, MAVS was only significantly upregulated at $21 \mathrm{dpi}$. In the kidney, $L G P 2$ was significantly upregulated at $5 \mathrm{dpi}$; however, some other 


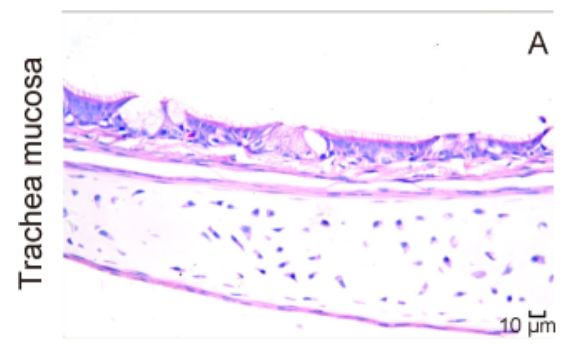

Control

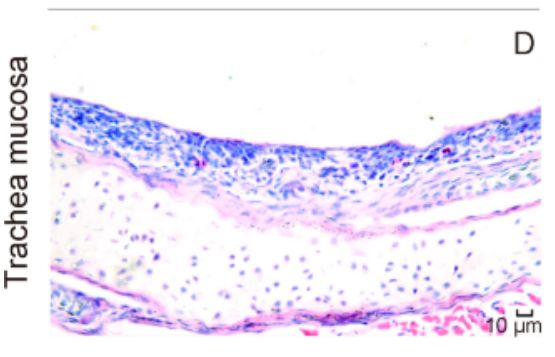

$8 \mathrm{dpi}$

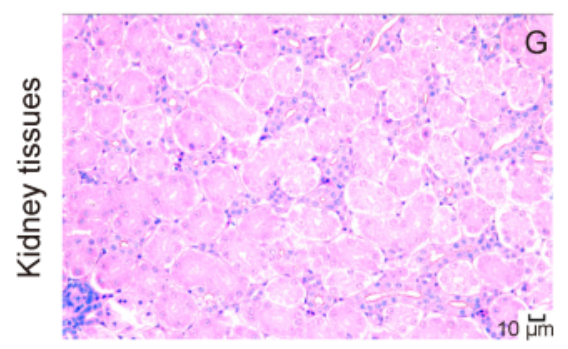

Control

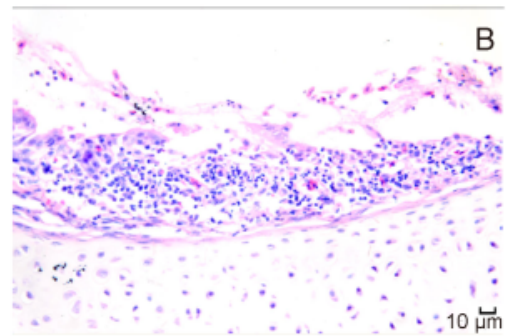

$3 \mathrm{dpi}$

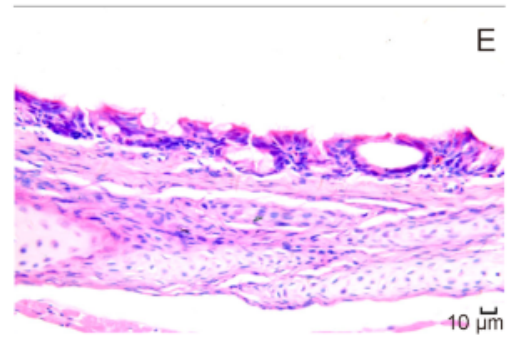

11 dpi

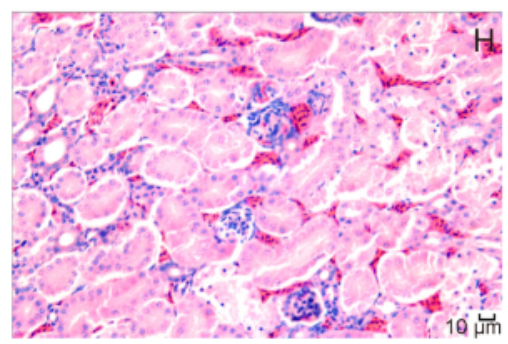

$8 \mathrm{dpi}$

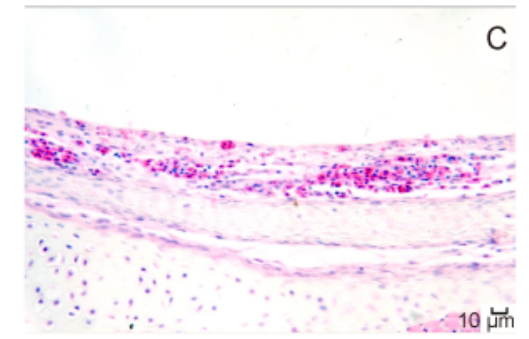

5 dpi

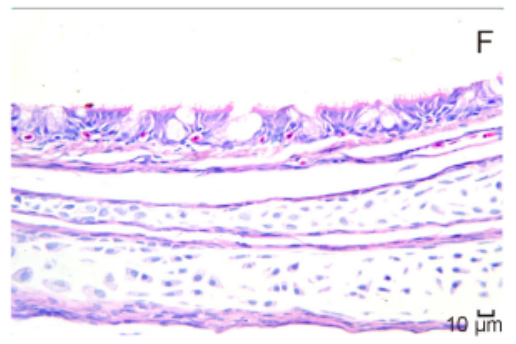

14 dpi

Figure 1. Microscopic changes in the trachea and kidneys of chicks infected with IBV. Hematoxylin and eosin staining is shown. Bar $=10 \mu \mathrm{m}$. (A and $\mathrm{G}$ ) The trachea and kidney from control group, showing no microscopic alterations. (B) Loss of the tracheal cilia, destruction of the structure, acute necrosis of epithelial cells, and infiltration of mononuclear lymphocytes and heterophils were found at $3 \mathrm{dpi}$. (C) The tracheal mucosa exhibited severe capillary hyperemia and inflammatory cell infiltration at $5 \mathrm{dpi}$. (D) Slight recovery of epithelial cell proliferation with lymphocyte infiltration at 8 dpi. (E): Epithelial cells were converted to columnar cells, and a few cilia appeared at $11 \mathrm{dpi}$. (F) The tracheal mucosa reached the normal level at $14 \mathrm{dpi}$. $(\mathrm{H})$ Hyperemia and degeneration in the kidney at $8 \mathrm{dpi}$, with nuclear enrichment in renal tubular epithelial cells and lymphocytic infiltration.

genes exhibited significant downregulation in the kidney.

Upregulation of TRAF3 and TRAF6 mRNA was observed in the trachea and kidney throughout the experiment (Figure 4E, 4F). As downstream genes, $T B K 1$, $I K K \varepsilon, I K K \alpha, I K K \beta, I R F 7$ and $N F-\kappa B$, which activate to produce type I IFN, pro-inflammatory cytokines and chemokines, exhibited contradictory changes in the two tissues, with significant upregulation at $1-8$ dpi and 21 dpi in the trachea and significant downregulation at 1-28 dpi in the kidney.

\section{Expression of innate immune cytokines in tissues after IBV infection}

Analysis of the expression levels of two type I IFN mRNAs showed that both molecules were distinctly up- regulated in the trachea and downregulated in the kidney (Figure 5). The mRNA expression of $I F N-\alpha$ had two peaks at 3 and $21 \mathrm{dpi}$, respectively, whereas that of and $I F N-\beta$ peaked at 5 and 21 dpi in infected trachea tissues. The mean concentrations of IFN- $\alpha$ and IFN- $\beta$ were significantly increased at 3,5 , and 21 dpi compared with that in the uninfected group (Figure 5B, 5C). However, at 14 and $21 \mathrm{dpi}$, inconsistent mRNA and protein levels were observed in the kidney (Figure 5A, 5C).

The expression levels of mRNAs encoding inflammatory cytokines, including $I L-1 \beta, I L-6, I L-10$, and $I L-12$, showed similar trends, with significant increases in the infected trachea and peaks at 5 dpi, lasting until 14 dpi (Figure 5A). Significantly higher concentrations of IL$1 \beta$, IL-6, and IL-10 at 8 dpi were also observed com- 


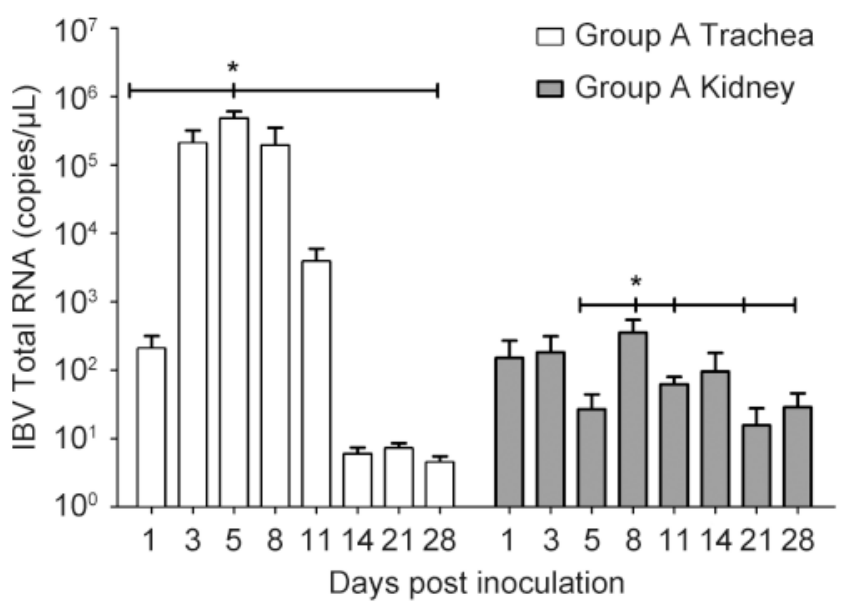

Figure 2. IBV total RNA in the trachea and kidney tissues after IBV M41 infection. Error bars indicate SEMs. Asterisks indicate significant differences among values at different time points $(P<0.05)$.

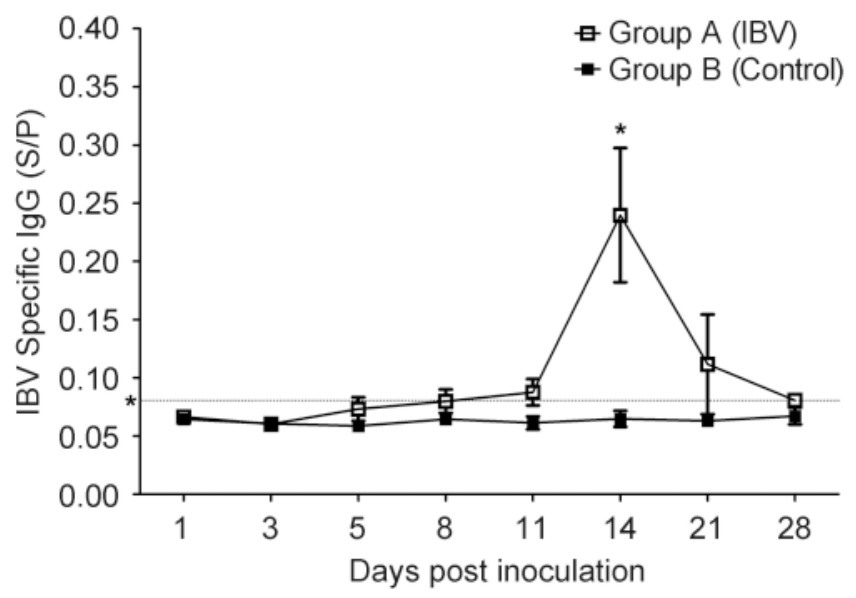

Figure 3. The level of IBV-specific IgG antibodies in the serum after IBV M41 infection. Error bars indicate SEMs. Asterisks indicate significant differences among values at different time points $(P<0.05)$. The asterisk along the dotted line at 0.08 on the $y$-axis indicates IgGpositive serum with an $S / P$ value of $>0.08$.

pared with those in the control group, and IL-12 was also upregulated at 3-21 dpi (Figure 5B, 5C). In contrast, the mRNA expression levels of these cytokines were downregulated in the kidney, except for $I L-1 \beta$, which was significantly upregulated (Figure 5A).

The mRNA levels of $I L-8$ and $M I P-1 \beta$ were significantly upregulated in both infected tissues, with a peak at 5 dpi in the trachea (Figure 5A); however, the protein levels of these two chemokines were quite different (Figure $5 \mathrm{~B}, 5 \mathrm{C})$. The mean concentration of IL-8 was significantly increased in the infected trachea at 3-21 dpi and was markedly higher than that in the control group at 14 and $21 \mathrm{dpi}$ in the kidney. However, MIP-1 $\beta$ was only higher than the control group at $11 \mathrm{dpi}$ in the trachea, and no significant changes were observed in the kidneys of chicks from both groups.

\section{DISCUSSION}

In this study, we monitored the infection course of IBV M41-challenged birds. The results showed that more pronounced histopathological lesions and higher of IBV loads were discovered in the trachea during early stages of the infection, consistent with previous studies (Benyeda et al., 2009; Fan et al., 2012; Okino et al., 2014), suggesting that the trachea was the target tissue for infection by the IBV M41 strain. Copy numbers of viral RNA in both the trachea and kidney at 1 dpi were similar because the virus spread throughout the body of the host via viremia (Wickramasinghe et al., 2014). However, IBV RNA was detected in the kidney with a considerable lower copy number, suggesting that IBV M41 infected and replicated somewhat in the kidney. Hyperemia and degeneration in the kidney were found from 8 dpi, which may be associated with tissue tropism of IBV.

Because TLRs, MDA5, and adapter molecules are involved in recognition of IBV RNA (Guo et al., 2008; Cong et al., 2013; Xu et al., 2015), we examined the mRNA dynamics of TLR3,TLR7, MDA5, and downstream signaling molecules at different phases in the trachea and kidneys of IBV-infected chickens. The results showed that in the early phase of infection, both $T L R 3$ and $T L R 7$ transcripts were significantly upregulated in the trachea at 3-8 dpi, but were only upregulated at 5 or 3 dpi in the kidney, respectively. Additionally, $M y D 88$ was significantly upregulated at $1-3$ dpi in the trachea. Concurrently, MDA5, LGP2, and STING transcripts were upregulated in the trachea at 1-28 dpi. Since the IBV load was rapidly increased in the trachea during this period, with limited expression in the kidney, the invasion and replication of IBV may result in the generation of massive viral RNA, including ssRNA, dsRNA, and other RNA intermediates, which are recognized by TLR3, TLR7, and MDA5 and lead to activation of various signaling pathways, as previously reported (Kint et al., 2015).

However, contradictory changes in gene expression in the trachea and kidney may be associated with the distinct viral loads at different time points and in different tissues, which depends on the specific IBV strain (Kameka et al., 2014; Xu et al., 2015). Notably, TLR7 and TRIF were significantly upregulated at $21 \mathrm{dpi}$ in both tissues; MAVS was upregulated at $21 \mathrm{dpi}$; and $M D A 5, L G P 2$, and STING were upregulated at 14-28 dpi. Thus, these data provided the first evidence showing that the TLR and MDA5 signaling pathways were in- 

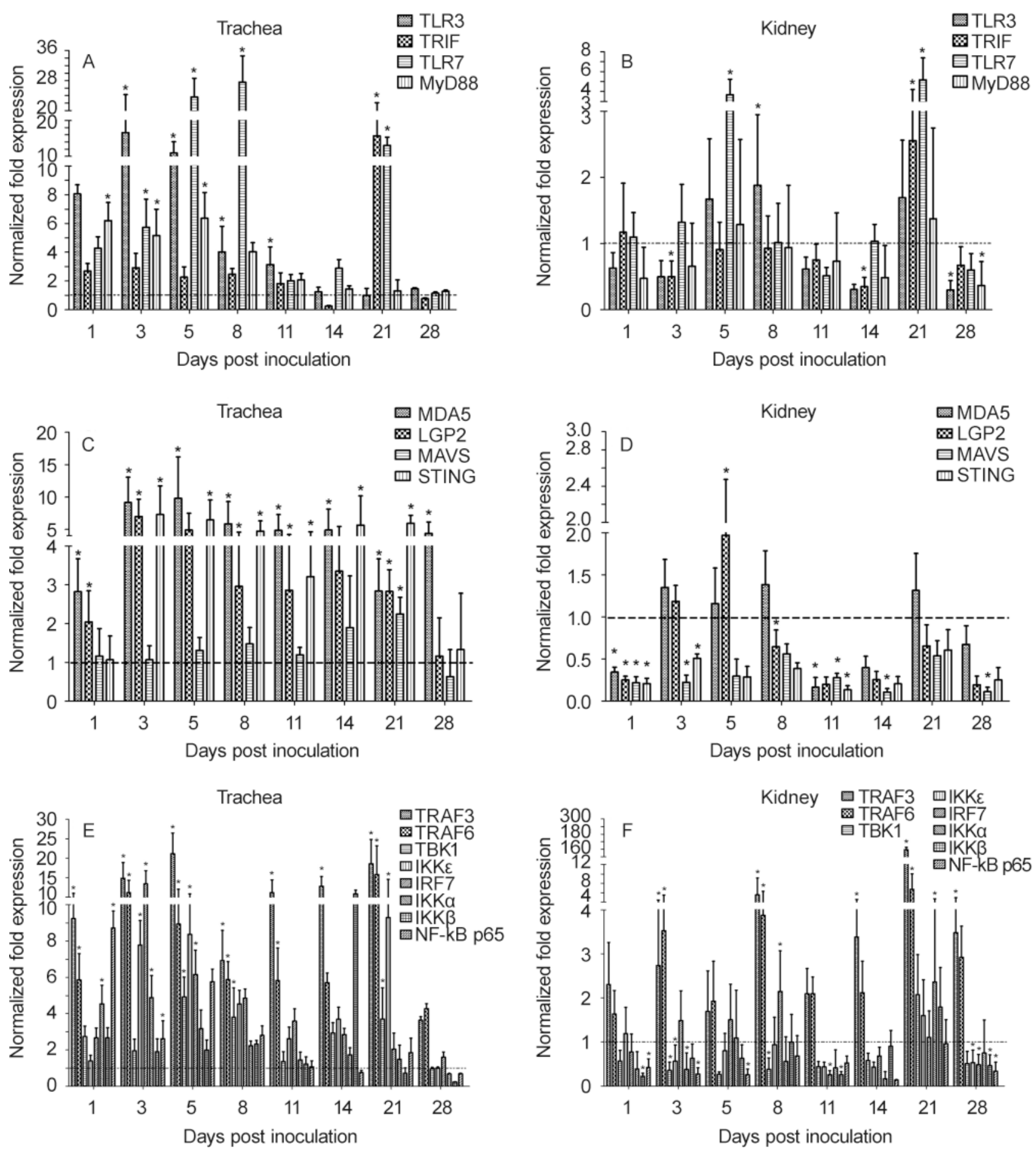

Figure 4. Relative mRNA expression levels of TLR3, TLR7, MDA5, and associated signaling molecules in IBV M41-infected trachea and kidney specimens. Error bars indicate SEMs. Asterisks indicate significant differences among different time points $(P<0.05)$.

volved in the late stage of IBV infection, despite the observation that the viral load was low during this period. Nevertheless, we found that the mRNA and protein levels of type I IFN were upregulated and increased dur- ing the same time period; $M D A 5$ is an IFN-stimulated gene (ISG) that can be induced by type I IFN (Sun et al., 2012). Therefore, this mechanism may be involved in the observed changes in gene expression, and further studies 

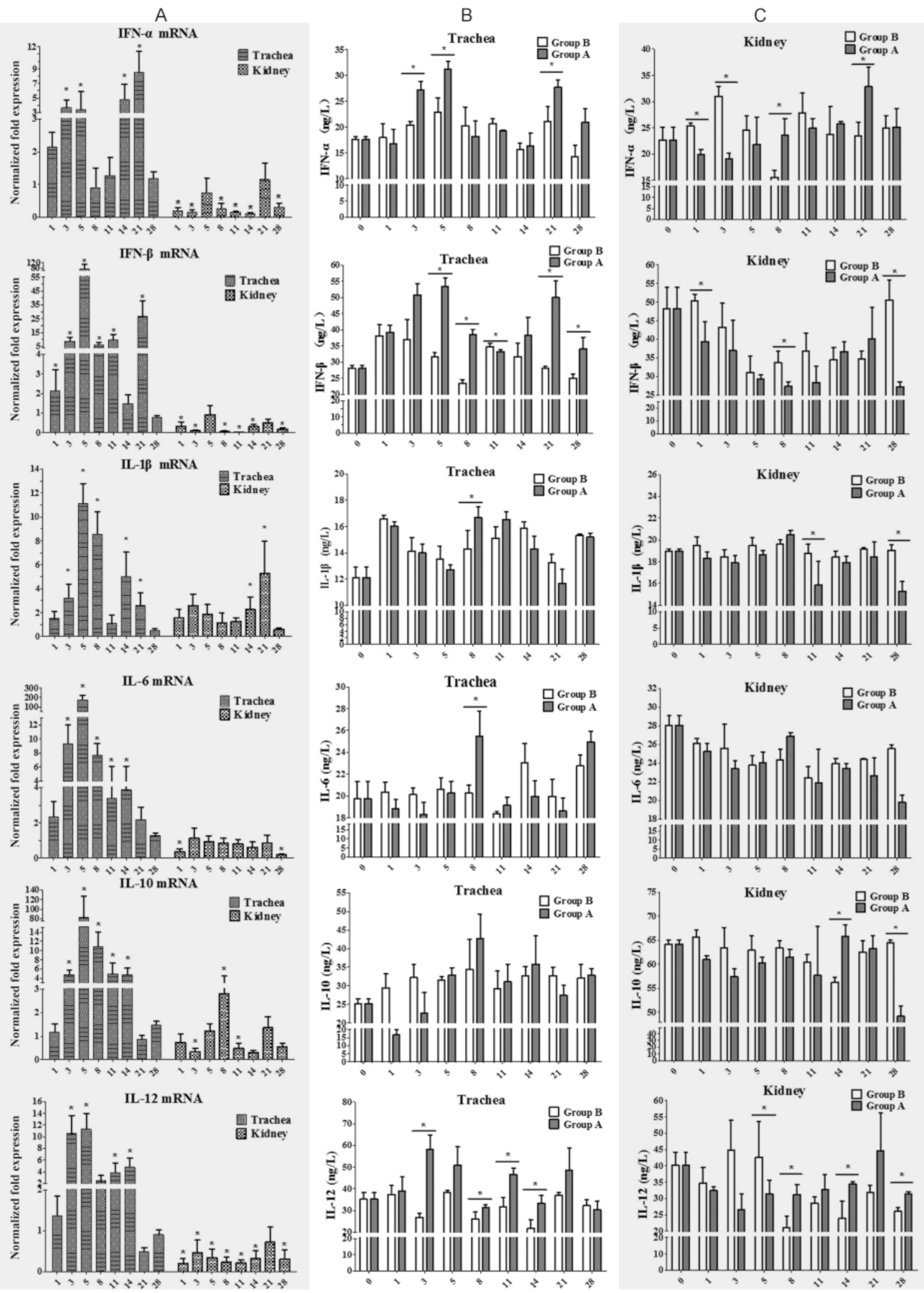

To be continued 
A

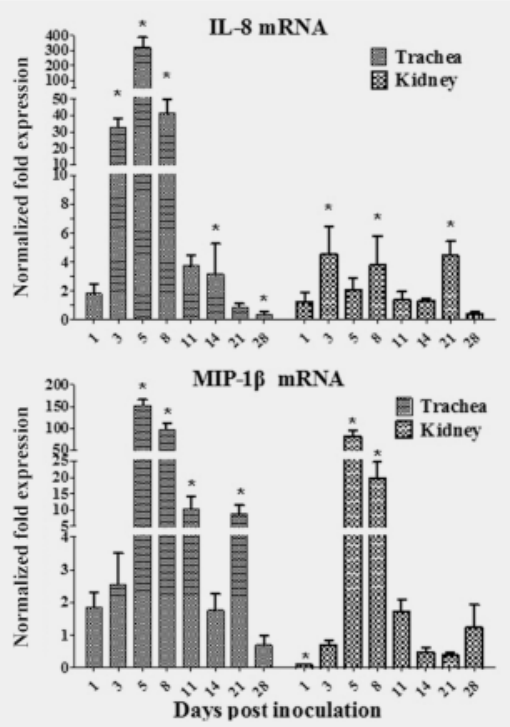

B

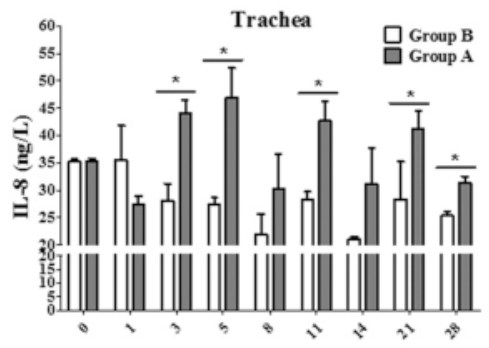

Trachea

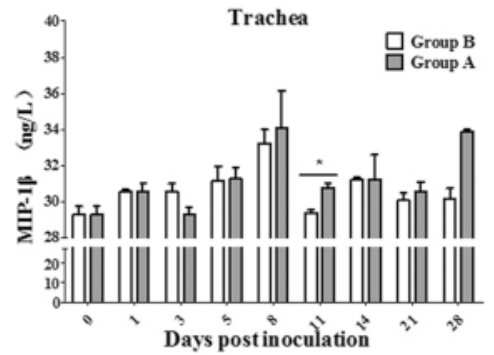

C
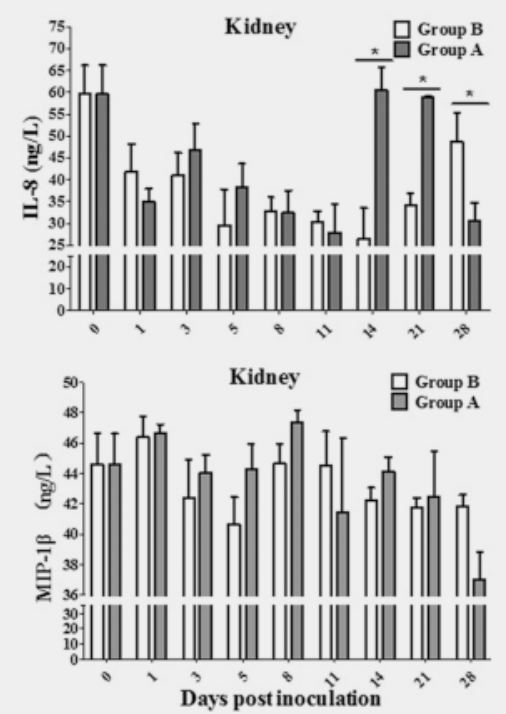

Figure 5. Changes in the gene expression and protein level of type I IFN, inflamatory cytokines, and chemokines in IBV M41-infected trachea and kidney tissues. The expression levels of mRNAs were detected by real-time qPCR (A). The protein levels of the targets were detected in the trachea $(B)$ and kidney $(C)$ using ELISA kits. Error bars indicate SEMs. Asterisks indicate significant differences among time points $(P<0.05)$.

are required to elucidate the specific details of such mechanisms.

We found that the downstream genes TRAF6 and $T R A F 3$ were significantly upregulated in both tissues throughout the experiment. This observation could be explained by the fact that these two molecules are common kinases involved in multiple signal pathways (Takeuchi and Akira, 2009). Alternatively, TRAF6 and TRAF3 complexes are inactivated by pathogenic microbes to limit or terminate pro-inflammatory and type I IFN and evade host innate immunity (Shi et al., 2014; Panda et al., 2015). In contrast, the mRNA levels of $M A V S, T B K 1$, $I K K \varepsilon, I K K \alpha, I K K \beta, I R F 7$, and $N F-\kappa B p 65$ exhibited more tight regulation in the infected trachea because upregulation of nuclear transcription factors depends on upstream molecules, whereas most genes were significantly downregulated in the kidney. Thus, the different responses and levels of activation of the TLR and MDA5 signal pathways after IBV infection may be related to the threshold of viral loads in the two tissues.

Importantly, changes in type I IFN, inflammatory cytokines, and chemokines in response to IBV infection were observed at both the transcript and protein levels. We observed consistent changes in TLR and MDA5 signaling pathway molecules and these cytokines. Additionally, the mRNA levels of type I IFN, inflammatory cytokines, and chemokines were dramatically elevated during IBV infection in the trachea, similar to the results of previous studies (Jang et al., 2013; Dar et al., 2014; Okino et al., 2014; Kameka et al., 2014). However, fur- ther studies are needed to confirm and explain the significant downregulation of these targets, except for $I L-1 \beta$, $I L-8$, and $M I P-1 \beta$, in the kidney. Unexpectedly, we found simultaneous peaks in the expression of all cytokines, the viral load, and the presence of histopathological lesions at $5 \mathrm{dpi}$ in the trachea, suggesting that the antiviral effects of innate immune cytokines may be critical during the early stages of infection. Furthermore, the upregulation of $I F N-\alpha, I F N-\beta, I L-12$, and $I L-8$ also peaked at $21 \mathrm{dpi}$, despite the clearance of IBV from the trachea at that time point. These results indicated that innate immune cytokines were still under tight regulation during the late stages of IBV infection.

At the protein level, the results in the trachea showed that the kinetics of IFN- $\alpha$, IFN- $\beta$, IL- 12 , and IL- 8 protein were consistent with changes in transcript levels at 3-8 and 14-21 dpi. During the early stages of infection, these cytokines and chemokines were associated with the infiltration of lymphocytes and heterophils in the tracheal tissues. At 8 dpi, increases in IL-1 $\beta$, IL-6, IL-10, and MIP- $1 \beta$ proteins were delayed with respect to the peaks in mRNA expression and viral replication in the trachea; the most severe damage occurred in the tracheal tissue at this time point, and slight signs of recovery were observed. This observation may be explained by the common induction of cytokines in the former group by the RLR signaling pathway, which primarily contributes to IFN- $\beta$ induction (Kint et al., 2015). The cytokines in the latter group were only induced by the TLR signaling pathway, indicating that IBV infection may 
regulate the host inflammatory responses. However, the inconsistent expression levels of mRNAs and proteins in the kidney indicated that complicated regulatory mechanisms may exist; although both mRNA and protein were downregulated during the early stages of infection, and protein levels increased at a later stage of infection, when mRNA was downregulated. This may be explained by systemic regulation in the infected chickens.

In conclusion, we observed considerable activation of the innate immune response in the target tissues after infection with the avian coronavirus IBV M41 strain with respect to the TLR and MDA5 signaling pathways and innate immune cytokines. However, this response differed among tissues, with a general trend toward upregulation in the trachea and downregulation in the kidney. In addition, we found consistent responses for changes in TLR and MDA5 signaling pathway molecules, innate immune cytokines, and histopathology during the early stages of infection; however, complicated regulatory mechanisms may be present, particularly in the kidney. To the best of our knowledge, our results provide the most comprehensive analysis of the interplay between a Gammacoronavirus and the avian TLR and MDA5 signaling pathway response. Since most of these receptors and signal molecules are activated by posttranslational modification, such as ubiquitination, phosphorylation, to recognize virus and transmit signal, more research should be done to evaluate the activity and effect of TLR and MDA5 signaling pathway at the protein level.

\section{ACKNOWLEDGMENTS}

This work was supported by grants from the Natural Science Foundation of China (31360611 and 31160516) and Guangxi Natural Science Foundation (2013GXNSFCA01 9010 and 2014GXNSFDA118011).

\section{COMPLIANCE WITH ETHICS GUIDELINES}

The authors declare that they have no conflicts of interest. The research involving animals in this study was approved by the Institute of Animal Science and Technology of Guangxi University Animal Ethics Committee and was performed in accordance with relevant national and international guidelines.

\section{AUTHOR CONTRIBUTIONS}

$\mathrm{YH}, \mathrm{MM}$, and $\mathrm{PW}$ designed the experiments and revised the manuscript; YH, ZX, JH, YZ, and YC established the standard curve; $\mathrm{YH}$ and $\mathrm{ZX}$ performed viral infections and all experimental tests and data analyses; JD performed the histopathology analyses; TW performed viral infections; and YH wrote the manuscript. All authors read and approved the final manuscript.

\section{REFERENCES}

Awad F, Chhabra R, Baylis M, Ganapathy K. 2014. An overview of infectious bronchitis virus in chickens. World Poultry Sci J, 70: $375-383$.

Benyeda Z, Mato T, Suveges T, Szabo E, Kardi V, Abonyi-Toth Z, Rusvai M, Palya V. 2009. Comparison of the pathogenicity of QX-like, M41 and 793/B infectious bronchitis strains from different pathological conditions. Avian Pathol, 38: 449-456.

Cao L, Ge X, Gao Y, Ren Y, Ren X, Li G. 2015. Porcine epidemic diarrhea virus infection induces NF-kappaB activation through the TLR2, TLR3 and TLR9 pathways in porcine intestinal epithelial cells. J Gen Virol, 96: 1757-1767.

Cavanagh D. 2005. Coronaviruses in poultry and other birds. Avian Pathol, 34: 439-448.

Cavanagh D. 2007. Coronavirus avian infectious bronchitis virus. Vet Res, 38: 281-297.

Chen L, Zhang T, Han Z, Liang S, Xu Y, Xu Q, Chen Y, Zhao Y, Shao Y, Li H, Wang K, Kong X, Liu S. 2015. Molecular and antigenic characteristics of Massachusetts genotype infectious bronchitis coronavirus in China. Vet Microbiol. 181: 241-251.

Cheng Y, Sun Y, Wang H, Yan Y, Ding C, Sun J. 2015. Chicken STING Mediates Activation of the IFN Gene Independently of the RIG-I Gene. J Immunol, 195: 3922-3936.

Chousalkar KK, Roberts JR, Reece R. 2007. Comparative histopathology of two serotypes of infectious bronchitis virus ( $\mathrm{T}$ and $\mathrm{n} 1 / 88$ ) in laying hens and cockerels. Poult Sci, 86: 50-58.

Cong F, Liu X, Han Z, Shao Y, Kong X, Liu S. 2013. Transcriptome analysis of chicken kidney tissues following coronavirus avian infectious bronchitis virus infection. BMC Genomics, 14 743.

Cook JK, Jackwood M, Jones RC. 2012. The long view: 40 years of infectious bronchitis research. Avian Pathol, 41: 239-250.

Dar A, Tikoo S, Potter A, Babiuk LA, Townsend H, Gerdts V, Mutwiri G. 2014. CpG-ODNs induced changes in cytokine/chemokines genes expression associated with suppression of infectious bronchitis virus replication in chicken lungs. Vet Immunol Immunopathol, 160: 209-217.

Dosch SF, Mahajan SD, Collins AR. 2009. SARS coronavirus spike protein-induced innate immune response occurs via activation of the NF-kappaB pathway in human monocyte macrophages in vitro. Virus Res, 142: 19-27.

Fan WQ, Wang HN, Zhang Y, Guan ZB, Wang T, Xu CW, Zhang AY, Yang X. 2012. Comparative dynamic distribution of avian infectious bronchitis virus M41, H120, and SAIBK strains by quantitative real-time RT-PCR in SPF chickens. Biosci Biotechnol Biochem, 76: 2255-2260.

Frieman M, Ratia K, Johnston RE, Mesecar AD, Baric RS. 2009. Severe acute respiratory syndrome coronavirus papain-like protease ubiquitin-like domain and catalytic domain regulate antagonism of IRF3 and NF-kappaB signaling. J Virol, 83: $6689-6705$.

Guo X, Rosa AJ, Chen DG, Wang X. 2008. Molecular mechanisms of primary and secondary mucosal immunity using avian infectious bronchitis virus as a model system. Vet Immunol Immunopathol, 121: 332-343.

Ignjatovic J, Ashton DF, Reece R, Scott P, Hooper P. 2002. Pathogenicity of Australian strains of avian infectious bronchitis virus. J Comp Pathol, 126: 115-123. 
Jang H, Koo BS, Jeon EO, Lee HR, Lee SM, Mo IP. 2013. Altered pro-inflammatory cytokine mRNA levels in chickens infected with infectious bronchitis virus. Poult Sci, 92: 2290-2298.

Kameka AM, Haddadi S, Kim DS, Cork SC, Abdul-Careem MF. 2014. Induction of innate immune response following infectious bronchitis corona virus infection in the respiratory tract of chickens. Virology, 450-451: 114-121.

Karpala AJ, Lowenthal JW, Bean AG. 2008. Activation of the TLR3 pathway regulates IFNbeta production in chickens. Dev Comp Immunol, 32: 435-444.

Kawasaki T, Kawai T. 2014. Toll-Like Receptor Signaling Pathways. Front Immunol, 5: 461

Kint J, Fernandez-Gutierrez M, Maier HJ, Britton P, Langereis MA, Koumans J, Wiegertjes GF, Forlenza M. 2015. Activation of the Chicken Type I Interferon Response by Infectious Bronchitis Coronavirus. J Virol, 89: 1156-1167.

Law HK, Cheung CY, Sia SF, Chan YO, Peiris JS, Lau YL. 2009. Toll-like receptors, chemokine receptors and death receptor ligands responses in SARS coronavirus infected human monocyte derived dendritic cells. BMC Immunol, 10: 35.

Li M, Jiang JJ, He K, Sun XK, Liang XB, Zhang YQ, Liang YD, Mo ML, Wei TC, W P. 2012. The detection and comparative analysis of antibodies IB in clinical serum samples using the self-developed Indirect N-ELISA kits. Guangxi J Animal Husb Vet Med, 28: 195-197. (In Chinese)

Li M, Wang XY, Wei P, Chen QY, Wei ZJ, Mo ML. 2012. Serotype and genotype diversity of infectious bronchitis viruses isolated during 1985-2008 in Guangxi, China. Arch Virol, 157: 467-474.

Liniger M, Summerfield A, Zimmer G, McCullough KC, Ruggli N. 2011. Chicken Cells Sense Influenza A Virus Infection through MDA5 and CARDIF Signaling Involving LGP2. J Virol, 86: 705-717.

Li J, Liu Y, Zhang X. 2010. Murine Coronavirus Induces Type I Interferon in Oligodendrocytes through Recognition by RIG-I and MDA5. J Virol, 84: 6472-6482.

Li Y, Bang D, Handberg K, Jorgensen P, Zhang M. 2005. Evaluation of the suitability of six host genes as internal control in real-time RT-PCR assays in chicken embryo cell cultures infected with infectious bursal disease virus. Vet Microbiol, 110: $155-165$

Mazaleuskaya L, Veltrop R, Ikpeze N, Martin-Garcia J, NavasMartin S. 2012. Protective role of Toll-like Receptor 3-induced type I interferon in murine coronavirus infection of macrophages. Viruses, 4: 901-923.

Mo ML, Cheng QY, Hou JL, Fan WS, Li M, Wei P, Wei TC, Wei ZJ. 2011. Development of a real-time PCR assay for detection of infectious bronchitis virus. China Poultry, 41: 193-198. (In Chinese)

Mo ML, Li M, Huang BC, Fan WS, Wei P, Wei TC, Cheng QY, Wei ZJ, Lang YH. 2013. Molecular characterization of major structural protein genes of avian coronavirus infectious bronchitis virus isolates in southern china. Viruses, 5: 3007-3020.

Mogensen TH. 2009. Pathogen Recognition and Inflammatory Signaling in Innate Immune Defenses. Clin Microbiol Rev, 22: 240.

Nakhaei P, Genin P, Civas A, Hiscott J. 2009. RIG-I-like receptors: sensing and responding to RNA virus infection. Semin Immunol, 21:215-222.

Nii T, Isobe N, Yoshimura Y. 2014. Effects of avian infectious bronchitis virus antigen on eggshell formation and immunoreaction in hen oviduct. Theriogenology, 81: 1129-1138.

Okino CH, Santos IL, Fernando FS, Alessi AC, Wang X, Mon- tassier HJ. 2014. Inflammatory and cell-mediated immune responses in the respiratory tract of chickens to infection with avian infectious bronchitis virus. Viral Immunol, 27: 383-391.

Panda S, Nilsson JA, Gekara NO. 2015. Deubiquitinase MYSM1 Regulates Innate Immunity through Inactivation of TRAF3 and TRAF6 Complexes. Immunity, 43: 647-659.

Pfaffl MW, Horgan GW, Dempfle L. 2002. Relative expression software tool (REST) for group-wise comparison and statistical analysis of relative expression results in real-time PCR. Nucleic Acids Res, 30: e36.

Schalk AF, Hawn MC. 1931. An apparently new respiratory disease of baby chicks. J Am Vet Med Assoc, 78: 413-422.

Sheahan T, Morrison TE, Funkhouser W, Uematsu S, Akira S, Baric RS, Heise MT. 2008. MyD88 is required for protection from lethal infection with a mouse-adapted SARS-CoV. PLoS Pathog, 4: e1000240.

Shi CS, Qi HY, Boularan C, Huang NN, Abu-Asab M, Shelhamer JH, Kehrl JH. 2014. SARS-coronavirus open reading frame-9b suppresses innate immunity by targeting mitochondria and the MAVS/TRAF3/TRAF6 signalosome. J Immunol, 193: 3080-3089.

Smith J, Sadeyen J, Cavanagh D, Kaiser P, Burt DW. 2015. The early immune response to infection of chickens with Infectious Bronchitis Virus (IBV) in susceptible and resistant birds. BMC Vet Res, 11: 256.

Sun L, Xing Y, Chen X, Zheng Y, Yang Y, Nichols DB, Clementz MA, Banach BS, Li K, Baker SC, Chen Z. 2012. Coronavirus papain-like proteases negatively regulate antiviral innate immune response through disruption of STING-mediated signaling. PLoS One, 7: e30802.

Sun Y, Han M, Kim C, Calvert JG, Yoo D. 2012. Interplay between interferon-mediated innate immunity and porcine reproductive and respiratory syndrome virus. Viruses, 4: 424-446.

Takeuchi O, Akira S. 2009. Innate immunity to virus infection. Immunol Rev, 227: 75-86.

Totura AL, Whitmore A, Agnihothram S, Schafer A, Katze MG, Heise MT, Baric RS. 2015. Toll-Like Receptor 3 Signaling via TRIF Contributes to a Protective Innate Immune Response to Severe Acute Respiratory Syndrome Coronavirus Infection. MBio, 6: e615-e638.

Wickramasinghe INA, de Vries RP, Grone A, de Haan CAM, Verheije MH. 2011. Binding of Avian Coronavirus Spike Proteins to Host Factors Reflects Virus Tropism and Pathogenicity. J Virol, 85: 8903-8912.

Wu B, Peisley A, Richards C, Yao H, Zeng X, Lin C, Chu F, Walz T, Hur S. 2013. Structural basis for dsRNA recognition, filament formation, and antiviral signal activation by MDA5. Cell, 152: 276-289.

Xu Y, Zhang T, Xu Q, Han Z, Liang S, Shao Y, Ma D, Liu S. 2015. Differential modulation of avian $\beta$-defensin and Toll-like receptor expression in chickens infected with infectious bronchitis virus. Appl Microbiol Biot, 99: 9011-9024.

Yu L, Jiang Y, Low S, Wang Z, Nam SJ, Liu W, Kwangac J. 2001. Characterization of three infectious bronchitis virus isolates from China associated with proventriculus in vaccinated chickens. Avian Dis, 45: 416-424.

Zhong Y, Tan YW, Liu DX. 2012. Recent progress in studies of arterivirus- and coronavirus-host interactions. Viruses, 4: 980-1010.

Zou J, Chang M, Nie P, Secombes CJ. 2009. Origin and evolution of the RIG-I like RNA helicase gene family. BMC Evol Biol, 9: 85 . 